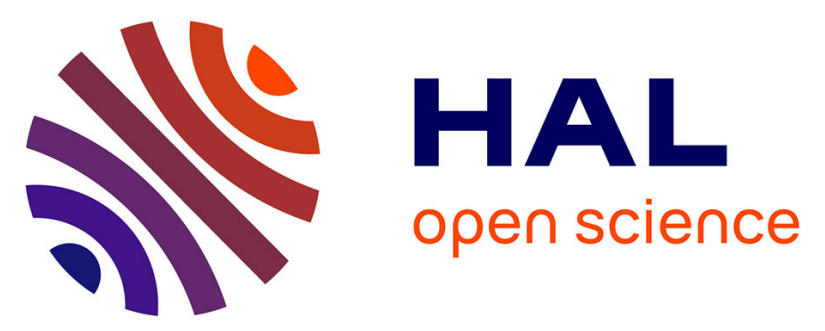

\title{
Autonomous Electric Vehicle Routing Problem using Ant Colony Optimization with consideration of the Battery State-of-Health
}

Pierre Romet, Romain Tabusse, Franck Gechter, El-Hassane Aglzim, Samir Jemei, David Bouquain, Daniela Chrenko

\section{To cite this version:}

Pierre Romet, Romain Tabusse, Franck Gechter, El-Hassane Aglzim, Samir Jemei, et al.. Autonomous Electric Vehicle Routing Problem using Ant Colony Optimization with consideration of the Battery State-of-Health. 2021 IEEE 33rd International Conference on Tools with Artificial Intelligence (ICTAI), Nov 2021, Washington, United States. pp.475-480, 10.1109/ICTAI52525.2021.00077 . hal03549351

\section{HAL Id: hal-03549351 \\ https://hal.science/hal-03549351}

Submitted on 31 Jan 2022

HAL is a multi-disciplinary open access archive for the deposit and dissemination of scientific research documents, whether they are published or not. The documents may come from teaching and research institutions in France or abroad, or from public or private research centers.
L'archive ouverte pluridisciplinaire HAL, est destinée au dépôt et à la diffusion de documents scientifiques de niveau recherche, publiés ou non, émanant des établissements d'enseignement et de recherche français ou étrangers, des laboratoires publics ou privés. 


\section{Autonomous Electric Vehicle Routing Problem using Ant Colony Optimization with consideration of the Battery State-of-Health}

\author{
$1^{\text {st }}$ Pierre Romet \\ CIAD \\ Univ. Bourgogne Franche-Comté \\ Belfort, France \\ pierre.romet@utbm.fr \\ $4^{\text {th }}$ El-Hassane Aglzim \\ ISAT-DRIVE \\ Univ. Bourgogne Franche-Comté \\ Nevers, France \\ el-hassane.aglzim@u-bourgogne.fr
}

$7^{\text {th }}$ Daniela Chrenko

FEMTO-ST Institute

Univ. Bourgogne Franche-Comté, UTBM, CNRS

Belfort, France

daniela.chrenko@utbm.fr

\author{
$2^{\text {nd }}$ Romain Tabusse \\ FEMTO-ST Institute \\ Univ. Bourgogne Franche-Comté, CNRS \\ Belfort, France \\ romain.tabusse@utbm.fr
}

\author{
$5^{\text {th }}$ Samir Jemei \\ FEMTO-ST Institute \\ Univ. Bourgogne Franche-Comté, CNRS \\ Belfort, France \\ samir.jemei@univ-fcomte.fr
}

\author{
$3^{\text {rd }}$ Franck Gechter \\ CIAD \\ Univ. Bourgogne Franche-Comté \\ Belfort, France \\ franck.gechter@utbm.fr
}

\author{
$6^{\text {th }}$ David Bouquain \\ FEMTO-ST Institute
}

Univ. Bourgogne Franche-Comté, CNRS

Belfort, France

david.bouquain@univ-fcomte.fr

\begin{abstract}
Freight transportation is evolving with the development of electric vehicle to carry out goods delivery rounds. In addition to the technological developments that make electric vehicles more and more suitable for long-distance traffic, the legislative framework also imposes these developments, such as the announced end of thermal vehicles in France in 2040. However, it is not possible to use an electric vehicle in the same way as an internal combustion vehicle. This technology impose to take into account the aging of the battery in order to define its use.

Index Terms-EVRP, ACO, autonomous vehicle, lithium-ion battery, SOE, SOH, DOD.
\end{abstract}

\section{INTRODUCTION}

For several years, a significant effort has been made to optimize the transport of goods in urban and peri-urban area. This improvement is mainly aimed at the reduction of the secondary effects such as road system congestion, air pollution and sound pollution. Thus, recent improvements to rationalize freight transport are mainly legislative such as the limitation of the size and weight of vehicles, the arrangement of vehicle schedules, urban distribution centers and last mile delivery. Furthermore, soft distribution circuits have emerged and new technologies as the electric car and autonomous vehicles are currently studied to resolve last mile delivery. In this context,

This work has been supported by the French State through the SURATRAM project, the Eco-Campus project, the EIPHI Graduate School and the Region Bourgogne Franche-Comté. Special thanks to the Régie des Transports du Territoire de Belfort for sharing their bus fleet data. vehicle routing problems (VRP) must be adapted to meet the specific requirements of these new technologies.

For this purpose, [12] presents a comprehensive overview about Electric Vehicle Routing Problem (EVRP). It begins with an introduction of EVRP issues linked to different technologies of battery. Then, the paper presents a non-exhaustive research work about EVRP possible variants, such as Energy Shortest Path Problem [9], Electric Traveling Salesman Problem, Heterogeneous or Mixed Vehicle Fleet [1], Hybrid Vehicles [12], Partial Recharging, Charging technologies and strategies [1], Battery Swapping, Two-Echelon Routing Problem, Charging Schedule and Dynamic Traffic Conditions.

However, the electric vehicle, due to the chemical nature of its battery, cannot be considered and used in the same way as a thermal one. Indeed, its recharge time is longer. Moreover, its performance will decrease over time in much larger proportions, especially its autonomy and power. To the authors' knowledge, this last point has never been considered in the EVRP.

In this paper, the development of a new freight transport system in urban area is proposed. It is based on autonomous electric vehicles that can move on city public transport system (dedicated bus lane). It will allow to transport goods from urban distribution center to all delivery points (bus stations) located in urban area [7]. To address the issue of battery aging, the influence of battery depth-of-discharge (DOD) is investigated. For this study, real data from a bus company and a battery aging database are used. 
The paper is structured as follow. Section II introduces all concepts and methods used. The section III describes experimental procedure. Then, Section IV presents the experimental results and a discussion about them. Finally, Section V summarizes the findings and states the main conclusions.

\section{MATERIALS AND METHODS}

This study investigates the last mile delivery of parcels within the city of Belfort using autonomous electric vehicles. For this, the city bus network is used as a support. The vehicle considered is a Tesla Model $\mathrm{S}$ in autonomous mode.

The objective of the study is to optimize the delivery of parcels by defining an adapted delivery strategy and an adequate sizing of the vehicle fleet. For this, the energy parameter will be particularly optimized. Indeed, for an autonomous electric vehicle, the main cost is related to the purchase of the vehicle and its energy consumption. It is also linked to the aging of the battery which will define the life span and therefore the replacement (or repurchase) of the battery.

Therefore, this work will complement the previous work on the EVRP, by taking into account the aging of the battery. For this purpose, an aging model based on the DOD, defining the vehicle's charge/charge strategies, will be used. It will allow to dimension the battery and then to calculate the financial cost of taking into account the aging. In addition, after the sizing of one vehicle, it will be possible to carry out the sizing of an entire fleet.

In the following, the main concepts for better understanding, algorithms and models used are presented. Then, the conducted experiments are described in details.

\section{A. EVRP}

This paper aims to optimize a last mile delivery logistics plan in city center, using autonomous electric vehicles. In order to determine a set of least energy cost delivery routes from an urban distribution centre (UDC) to delivery points, a Vehicle Routing Problem (VRP) algorithm adapted to electric vehicles (EVRP) is implemented. Our EVRP algorithm is based on a graph, where each edge contains the distance, the time and the energy information needed to travel through it.

The problem is solved under the following constraints:

- Each customer is visited only once by a single vehicle;

- Each vehicle must start and end its route at the urban depot;

- Total volume of packages, transport of the vehicle cannot exceed its volume capacity;

- Total energy consumed cannot exceed the energy capacity of the vehicle.

\section{B. $A C O$}

As the EVRP II-A is based on a graph, it was decided to implement an ant colony algorithm to exploit it and determine a tour that would minimize total energy consumption. For this, the ACO model implemented is the same as in [10], to which a termination criterion has been added. Thus, thanks to the maximum number of iterations calculated by the termination criterion, the optimal solution is found. The number of iterations to be performed is given by the equation 1 .

$$
\theta=\frac{\sum_{v=1}^{n} \omega_{i}}{k}
$$

With $v$ the number of vertices in the graph, $\omega_{i}$ the number of edges starting to the current vertex and connecting it to another vertex and $k$ the number of edges in the graph.

\section{Graph Building}

The graph is a replica of the public transportation system of the city of Belfort (France). Each node is a bus stop and edges are bus lanes on the road system of the city. Moreover, each edge is composed of calculating parameters: distance, time, packages volume to be dropped off and energy consumed to move between two bus stops.

These parameters were calculated thanks to data of the Régie des Transports du Territoire de Belfort (RTTB), concerning the traffic of buses on the city's public transport system. Over ten past years data, only one day was used in this work in a first approach. Their data are files storing at thirty-second intervals, successive GPS points forming the route taken by the bus during the day (KMZ file).

To calculate the parameters of each edge, all GPS points forming the path between two bus stops were extracted. Then time, distance and energy were calculated.

The distance of each edge is calculated using the WGS84 ellipsoid formula, based on the set of GPS points between two bus stops. In addition, the energy required to travel the edge is calculated with the energy model, described in section II-D.

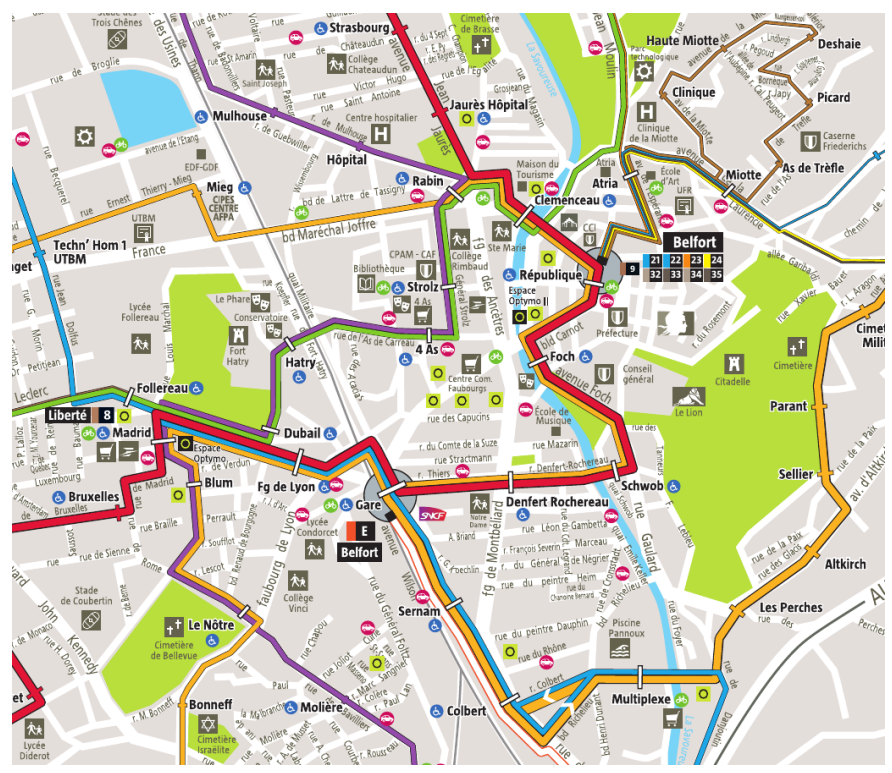

Fig. 1. Public transportation system of Belfort city

\section{Energy Model}

The energy of each edge of the graph is determined using the fundamental principle of dynamics applied to the vehicle 
illustrated in figure 2. Knowing the characteristics of the vehicle and its speed profile on the edge covered, the mechanical power at the wheels $P_{\text {wheels }}$ necessary for its movement at any time can be determined by equation 2 .

$$
\begin{aligned}
P_{w h e e l s}=v_{v e h} & \left(M_{v} \frac{d v_{v e h}}{d t}+\frac{1}{2} \rho_{a i r} v_{v e h}^{2} S C_{x}\right. \\
+ & \left.M_{v} g \sin (\alpha)+M_{v} g C_{r} \cos (\alpha)\right)
\end{aligned}
$$

where:

$v_{v e h}$ is the vehicle's speed in $m . s^{-1}$,

$\alpha$ is the road grade in $r a d$,

$g$ is the acceleration of gravity in $m . s^{-2}$,

$\rho_{\text {air }}$ is the air density at sea level at $15^{\circ} \mathrm{C}$,

$M_{v}$ is the vehicle's mass in $k g$,

$C x$ is the drag coefficient of the vehicle,

$S$ is the frontal area of the vehicle in $m^{2}$,

$C_{r}$ is the rolling resistance coefficient.

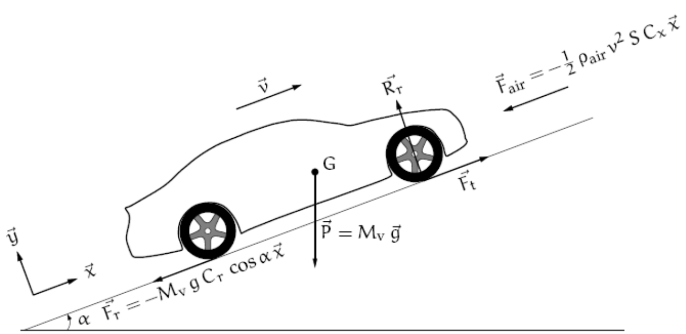

Fig. 2. Balance of forces applied to the vehicle. The inertia of the rotating masses is not taken into account.

The vehicle's speed $v_{v e h}$ is determined using the RTTB's GPS database by deriving the position of the bus as a function of time. Given the low sampling rate of the GPS data used (one sample every $30 \mathrm{sec}$ ), only the average speed of the vehicle is considered over an edge (zero acceleration and zero energy recovery).

Similarly, the slope calculation is done over an edge from the difference in elevation between the first point of the edge and the last one by equation 3 .

$$
\alpha_{\text {edge }}=\arctan \left(\frac{\Delta \text { Elevation }}{\text { Distance }}\right)
$$

Thus the equation 2 simplifies and gives the average power required over an edge. After multiplying by the travel time $\Delta t$, we find the energy required to move the vehicle on the edge. Finally, considering a constant powertrain (PWT) efficiency $\eta_{P W T}$, the energy supplied by the vehicle's battery to cover the edge is given by equation 4 .

$$
E_{\text {edge }}=\eta_{P W T} * P_{\text {wheels }} * \Delta t
$$

To calculate the corresponding energy for each edge, equation 4 is used with the Tesla Model S 90D (2017) vehicle's parameters shown in table I [6].
TABLE I

ENERGY MODEL PARAMETERS

\begin{tabular}{|c|c|}
\hline Parameters & Numeric value \\
\hline$\rho_{a i r}$ & $1.225 \mathrm{~kg} . \mathrm{m}^{-3}$ \\
\hline$g$ & $9.81 \mathrm{m.s}$ \\
\hline$M v$ & $2199 \mathrm{~kg}$ \\
\hline$S C x$ & 0.56 \\
\hline$C r$ & 0.012 \\
\hline$\eta_{P W T} W$ & 0.90 \\
\hline
\end{tabular}

\section{E. Battery State of Health \& Aging Model}

The aging of a battery is commonly defined as an irreversible loss of its performance. The most commonly used indicator is the battery capacity expressed in Ah. The state of health $(\mathrm{SOH})$ of a battery is defined as the ratio of its remaining capacity to its initial capacity measured when new (equation 5). It is most often expressed as a percentage. A new battery corresponds to an SOH of $100 \%$, while a battery at end-of-life usually corresponds to an $\mathrm{SOH}$ of about $80 \%$ in electric cars [4].

$$
S O H=\frac{\text { currentCapacity }}{\text { initialCapacity }}
$$

The SOH of a battery can be determined by direct measurement or by modeling. Concerning the last, a large number of approaches exist [13]. Here an empirical data based approach is considered.

For this purpose, battery aging data from an open access database have been used [8]. The cells studied here are the Panasonic B in 18650 format. They are used in the Tesla Model S vehicle presented previously. Considering a linear battery aging from $100 \% \mathrm{SOH}$ to $80 \%$, a linear model has been established from the aging database. Thus, the life cycle of the cell considered is given for three different DOD in table II: $20 \%, 60 \%$ and $100 \%$. The cycle life is given in number of cycles performed at a given DOD until reaching a SOH of $80 \%$. Therefore, the SOH of the battery for each DOD considered is proportional to the energy that passed through it.

TABLE II

BATTERY CYCLE LIFE AS A FUNCTION OF DOD. END-OF-LIFE IS REACH BY $80 \% \mathrm{SOH}$

\begin{tabular}{|c|c|c|c|}
\hline DOD(\%) & 100 & 60 & 20 \\
\hline Cycle life & 363 & 1220 & 6595 \\
\hline
\end{tabular}

\section{F. Delivery List Generator}

In order to be consistent with a real last mile delivery application, it is necessary to determine the number of parcels dropped off per delivery point, their size and volume.

First of all, [11], [5], [2] make it possible to identify that a set of 1 to 6 parcels is deposited on each delivery point of the tour, according to their weight and their volumes. In addition, the company Amazon provides a comprehensive list of all the packages it processes by weight and volume III. 
TABLE III

PACKAGE TYPE

\begin{tabular}{|r|c|}
\hline Package Type & Volume $\left(\mathrm{m}^{3}\right)$ \\
\hline \multicolumn{2}{|c|}{ Standard Envelope } \\
\hline small format & 0.0003 \\
standard format & 0.0018 \\
large format & 0.0037 \\
\hline \multicolumn{2}{|c|}{ Standard Parcel } \\
\hline \multicolumn{2}{|c|}{0397} \\
\hline Oversized Parcel \\
\hline small parcel & 0.1290 \\
standard parcel & 0.4320 \\
large parcel & 2 \\
\hline
\end{tabular}

Based on the number of packages per delivery point [11], [5], [2] and Amazon's package format III. The generated list of packages to be delivered is defined as being arbitrarily made up of 50\% standard letter, 35\% standard package and $15 \%$ oversized package.

\section{RESUlts GENERATION}

\section{A. From EVRP to EAHVRP}

As introduced in the section II-A, an EVRP coupled with the use of an autonomous vehicle II is used on our graph II-C to optimise the tour to deliver all the packages.

The optimization phase is performed by the ant colony algorithm II-B, which at each iteration will weight the parameters distance, time, volume, energy of each edge constituting the tour generated by an ant. Each parameter is weighted differently. The total energy needed to move on an edge is weighted by a factor of 0.5 . The total volume of parcels to be delivered to the next delivery point is weighted by a factor of 0.3 . The time and distance to travel an edge is weighted by a factor of 0.1 .

Working on last mile delivery, three lists of goods were generated according to the model defined in II-F, in order to study three typical problem sizes, as illustrated by [11].

The three graphs are composed of 30, 60 and 80 delivery points randomly and homogeneously distributed on the graph.

In addition, to meet the criteria of a last mile application, the Urban Distribution Centre (UDC) was placed in the centre of the city. More precisely at the railway station, this allows the UDC to be supplied by rail so as not to impact the city's road system.

Thus, after exploiting the three graphs with our AEVRP algorithm, a tour minimizing the energy needed to visit each of the delivery points was generated. Moreover, as introduced in II-E, optimising the energy needed for a tour minimizes the impact on battery aging. Finally, the phenomenon of aging of the vehicle battery is studied through the influence of different DOD strategies III-C.

Together these elements allow us to define our new variant of the EVRP, the Electric Autonomous Heatlth Vehicle Routing Problem (EAHVRP).

\section{B. DOD strategy}

Nowadays, different technologies for charging batteries are available. A slow charge made with $; 7 \mathrm{~kW}$ chargers allows to recharge the battery between 6 and 8 hours. A fast charge, carried out in 1-2 hours, uses chargers with a power ranging from 11 to $43 \mathrm{~kW}$. Finally, a super charger with a power of 50 to $250 \mathrm{~kW}$ can recharge Tesla's battery in a maximum of 45 minutes [1].

However, it must be taken into account that each type of recharge (slow, fast, accelerated) has a different impact on the aging of the battery [3]. The capacity of a battery degrades at $80 \%$ of its initial value more quickly with a fast or accelerated recharge, so these contribute greatly to the acceleration of the aging processus.

Moreover, the section III-C explains the approach to sizing a battery to maximize its life. A vehicle is therefore designed to make the best use of a given capacity range, depending on the DOD strategy, to complete its tour, which varies between $5 \mathrm{am}$ and $18 \mathrm{pm}$. Once the tour is over, the vehicle has the whole night to recharge, i.e. between 18 p.m. and 5 p.m., allowing the use of a slow charge. In this context, an electric vehicle will perform one charge/discharge cycle per day.

Furthermore, according to [8], three different DOD strategy has been defined to study the impact of the battery aging on the battery. The state of health of the battery defining the number of cycle and the time of use of the vehicle, the aging process impact as well as the number of packages deliver and the financial impact of the vehicle over its lifetime. The following DOD strategies are consider: 100\%DOD (from 100\% to $0 \%$ SOC), $60 \%$ DOD (from $80 \%$ to $20 \%$ SOC), $20 \%$ DOD (from $60 \%$ to $40 \%$ SOC).

Having defined the DOD strategies to be used in our study, it remains to size the battery capacity according to them.

\section{Battery Energy Capacity Sizing}

Being able to determine the energy required to complete a tour, it remains to calculate the battery energy capacity $E_{\text {battery }}$ according to the DOD strategy used. For this, the equation 6 is use.

$$
E_{\text {battery }}=E_{\text {needed }} / D O D(\%) / 20 \%
$$

where the $20 \%$ coefficient corresponds to the loss of capacity of the battery at the end of its life.

\section{RESUlTS}

\section{A. EAHVRP Results and Solution Set}

The presentation of the research results is organised as follows. First, the solutions generated by the EAHVRP algorithm will be introduced (III-A), and then an analysis of these solutions combined with the different DOD strategies studied will be provided.

For each size of graph presented in the part II-C, the EAHVRP algorithm generated a set of possible solutions to achieve the delivery of goods IV.

Before continuing, it is necessary to consider a counterintuitive fact concerning the number of rounds. Thanks to the 
first line of the table IV of the set of solutions of the 80 points graph, we observe that a low number of rounds is not necessarily linked to a low energy consumption. Thus, the solution having consumed the least energy will have made one more cycle than the others to carry out its tour. The same procedure is followed for the other two data sets in order to select the best solution. These solutions can be found in the table V.

TABLE IV

RESULTS FOR DIFFERENT GRAPH SIZE

\begin{tabular}{|c|c|c|c|c|}
\hline Distance $(\mathrm{km})$ & Energy $(\mathrm{kWh})$ & Time $(\mathrm{h})$ & Volume $\left(\mathrm{m}^{3}\right)$ & Turn \\
\hline \multicolumn{5}{|c|}{ Graph 30 points } \\
\hline 86.6 & 13575 & 4.55 & 1.95 & 2 \\
\hline 89.03 & 13798 & 4.70 & 1.97 & 2 \\
\hline 89.16 & 13871 & 4.73 & 1.96 & 2 \\
\hline 89.03 & 13936 & 4.71 & 1.19 & 2 \\
\hline \multicolumn{5}{|c|}{ Graph 60 points } \\
\hline 157.07 & 24401 & 9.38 & 2.32 & 5 \\
\hline 160.71 & 24460 & 9.30 & 2.39 & 5 \\
\hline 162.86 & 24567 & 9.79 & 2.23 & 5 \\
\hline 164.18 & 24920 & 9.41 & 2.20 & 5 \\
\hline \multicolumn{5}{|c|}{ Graph 80 points } \\
\hline 218.29 & 34948 & 13.32 & 2.32 & 7 \\
\hline 223.19 & 35525 & 13.53 & 2.39 & 6 \\
\hline 224.54 & 36423 & 12.97 & 2.23 & 6 \\
\hline 219.86 & 36452 & 13.02 & 2.20 & 6 \\
\hline
\end{tabular}

TABLE V

DATASET OF SOLUTION MINIMIZING TOTAL ENERGY CONSUMED

\begin{tabular}{|l|l|l|l|l|l|}
\hline $\begin{array}{l}\text { Graph } \\
\text { size }\end{array}$ & Turn & $\begin{array}{l}\text { Energy } \\
(k W h)\end{array}$ & $\begin{array}{l}\text { Volume } \\
\left(m^{3}\right)\end{array}$ & $\begin{array}{l}\text { Distance } \\
(k m)\end{array}$ & $\begin{array}{l}\text { Time } \\
(h)\end{array}$ \\
\hline 30 & 2 & 13575 & 1.95 & 86.6 & 4.55 \\
\hline 60 & 5 & 24401 & 2.32 & 157.07 & 9.38 \\
\hline 80 & 7 & 34948 & 2.32 & 218.29 & 13.32 \\
\hline
\end{tabular}

\section{B. Battery Sizing Results}

From the set of solutions selected in Table V, it is possible to calculate the minimum energy capacities required for an electric vehicle to complete its tour, depending on the DOD strategy used (II-E). Results are shown in Table VI.

TABLE VI

BATTERY ENERGY CAPACITY ACCORDING TO DOD STRATEGIES

\begin{tabular}{|c|c|c|c|}
\hline Delivery points & $\mathbf{1 0 0 \%}$ DOD & $\mathbf{6 0 \%}$ DOD & 20\% DOD \\
\hline 30 & $16.96 \mathrm{kWh}$ & $28.28 \mathrm{kWh}$ & $84.84 \mathrm{kWh}$ \\
\hline 60 & $30.50 \mathrm{kWh}$ & $50.84 \mathrm{kWh}$ & $152.50 \mathrm{kWh}$ \\
\hline 80 & $49.93 \mathrm{kWh}$ & $83.23 \mathrm{kWh}$ & $249.67 \mathrm{kWh}$ \\
\hline
\end{tabular}

Thus, it is possible to define 9 vehicles operating in 9 different scenarios on three graph sizes. They provide a set that best characterizes the battery size of a vehicle. However, four vehicles are set aside for our study. Those with an energy capacity below $30 \mathrm{kWh}$ and those with an energy capacity above $100 \mathrm{kWh}$.

Indeed, the energy model II-D is designed to calculate the energy necessary to move a $2199 \mathrm{~kg}$ vehicle with a battery of $90 \mathrm{kWh}$. Knowing that decreasing the energy capacity of the battery is equivalent to decreasing its mass, our model is no longer valid for solutions with a consumption of less than $30 \mathrm{kWh}$ and conversely for consumptions greater than 100 $\mathrm{kWh}$. Considering an energy density of $250 \mathrm{Wh} / \mathrm{kg}$, reducing a battery by $1 \mathrm{~kW}$ means reducing its mass by $4 \mathrm{~kg}$. As mass is a significant part of the energy model equation, it is not possible to exploit these results without distorting our study.

From this, it must be understood that the extremes are amplified. Thus, for batteries with an energy capacity of less than $30 \mathrm{kWh}$, their real energy capacities will be revised downwards and for batteries with an energy capacity of more than $100 \mathrm{kWh}$, their real energy capacities will be revised upwards.

Finally, concerning the analysis of the impact of aging on the battery, and thanks to the exploitation of open access data [8], it was possible to calculate the number of cycles achievable given the degradation factor, due to the DOD strategy used VII.

TABLE VII

NUMBER OF CYCLE CHARGE/DISCHARGE DUE TO DOD STRATEGIES BEFORE END-OF-LIFE

\begin{tabular}{|c|c|c|c|}
\hline Delivery points & $\mathbf{1 0 0 \%}$ DOD & $\mathbf{6 0 \%}$ DOD & 20\% DOD \\
\hline 30 & 363 & 1220 & 6595 \\
\hline 60 & 363 & 1220 & 6595 \\
\hline 80 & 363 & 1220 & 6595 \\
\hline
\end{tabular}

Thanks to the table VII, we can observe that, depending on the DOD strategy chosen, it has a major impact on the life of the battery. We can see that, for an equivalent energy capacity, between a DOD strategy of $100 \%$ and a strategy of $20 \%$, the life span in terms of number of cycles (III-B) is multiplied by 18 . Thus, due to the DOD strategy implemented III-B, the battery's lifetime in number of years varies between 1 year and over 18 years.

\section{Financial Cost}

Having been able to determine the impact of aging on the life of a battery, we now seek to determine its impact on the cost of purchase. Considering the price of $1 \mathrm{kWh}$ battery of $100 \$$, it is possible to put a price on each of the previously calculated energy capacities VI.

TABLE VIII

FINANCIAL COST FOR BATTERY ENERGY CAPACITY WITH DIFFERENT DOD STRATEGIES

\begin{tabular}{|c|c|c|c|}
\hline Delivery points & $\mathbf{1 0 0 \%}$ DOD & $\mathbf{6 0 \%}$ DOD & 20\% DOD \\
\hline 30 & $1697 \$$ & $2828 \$$ & $8484 \$$ \\
\hline 60 & $3050 \$$ & $5084 \$$ & $15251 \$$ \\
\hline 80 & $4994 \$$ & $8323 \$$ & $24968 \$$ \\
\hline
\end{tabular}

In the table VIII, it can be seen that the price of a battery using a DOD strategy of $100 \%$ is 4994 \$. For a battery using a $20 \%$ DOD strategy, its price is $8484 \$$. Furthermore, based on the table VII, we can see that using a DOD strategy of $20 \%$ makes it possible to minimize the aging phenomenon of 
a battery and thus multiply its life by 18 . Thus, it appears that implementing a DOD strategy of $20 \%$ certainly implies multiplying the price of a battery by 1.7 , but the lifetime of the latter is multiplied by 18 .

We are now interested in the impact of aging on the financial cost per delivery point.

TABLE IX

FINANCIAL COST FOR A DELIVER POINT

\begin{tabular}{|c|c|c|c|}
\hline Delivery points & $\mathbf{1 0 0 \%}$ DOD & $\mathbf{6 0 \%}$ DOD & 20\% DOD \\
\hline 30 & $0.156 \$$ & $0.077 \$$ & $0.043 \$$ \\
\hline 60 & $0.140 \$$ & $0.069 \$$ & $0.039 \$$ \\
\hline 80 & $0.172 \$$ & $0.085 \$$ & $0.047 \$$ \\
\hline
\end{tabular}

According to the table IX, we can see that for a $100 \%$ DOD strategy, a delivery point has a financial impact of $0.174 \$$, compared to $0.043 \$$ for a $20 \%$ DOD strategy.

It can be concluded that, although the "oversizing" linked to the DOD strategy of $20 \%$ multiplies the price of the battery by 1.7 , the financial impact of a delivery point is divided by $4(0.174 / 0.043=4)$.

\section{Fleet sizing}

Being able to size a vehicle, it is possible to continue this work to size a fleet of electric vehicles. The table $\mathrm{X}$ provides information on the energy cost of a graph according to the number of delivery points.

TABLE $\mathrm{X}$

AVERAGE ENERGY COST FOR A DELIVERY POINT

\begin{tabular}{|c|c|}
\hline Delivery points & Energy cost (kWh) \\
\hline 30 & 0.45 \\
\hline 60 & 0.40 \\
\hline 80 & 0.49 \\
\hline
\end{tabular}

As can be seen in the table $X$, the graph size that requires the least amount of energy to explore is 60 delivery points.

This result may seem counter-intuitive, but under-utilisation of the transport system (30 delivery points) implies long distances between each point, increasing consumption. Furthermore, over-utilisation ( 80 delivery points) leads to more detours between each point, thus increasing consumption.

This observation highlights the need for a detailed study on the sizing of a fleet of autonomous electric vehicles with heterogeneous energy capacity.

\section{CONCLUSION}

This article has studied the consideration of the problem of the aging of the battery of an electric vehicle through its use and its dimensioning.

Exploiting here a VRP problem with autonomous electric vehicles, we propose an Autonomous Electric Health VRP algorithm to address this problem. Having generated a set of solutions for three sizes of graphs II-C, traversed by vehicles exploiting different DOD strategies VI. We sought to define the impact of aging on the battery.
Through the results IV, we can conclude that the aging of lithium batteries is a key point for a good use of this technology in the transport field. Indeed, we have been able to show the importance of aging through its impact on the life of the vehicle IV-B, as well as on the financial aspect IV-C.

Thus, it can be concluded that the choice of the DOD strategy is the major element in the aging of a battery VII. In addition, although the use of a low percentage DOD strategy implies a larger battery size. Its lifetime is, however, multiplied by 18 . It can therefore be concluded that "over-consumption" of raw material is in this case preferable for sustainable management of natural resources. It should also be noted that since the battery degrades slowly, by minimizing the aging factor, this favours the second life of the battery.

Finally, taking account of aging is not a financial problem, as the factor for increasing battery life is more than 10 times higher than the factor for increasing battery price.

Finally, by analysing the energy cost per delivery point $\mathrm{X}$, we notice that the energy required depends on the size of the studied graph. This element opens the way to the continuation of our work, concerning the dimensioning of a fleet of autonomous electric vehicles of heterogeneous energy capacity.

\section{REFERENCES}

[1] J. Faulin J. Armas S. Grasman A. A. Juan, C. A. Mendez. Electric vehicles in logistics and transportation: A survey on emerging environmental, strategic, and operational challenges. Energies, 9, 2016.

[2] D. Erhel A. D. Moreau. La messagerie, une approche systémique pour appréhender les réseaux de transport de colis. Les Cahiers Scientifiques du Transport, 2008.

[3] Habib Al jed. Influence de la recharge rapide sur les performances des accumulateurs lithium des véhicules électriques dans le cadre de l'utilisation postale. Theses, Université de Bordeaux, 2014.

[4] Matthieu Dubarry, George Baure, and David Anseán. Perspective on State-of-Health Determination in Lithium-Ion Batteries. Journal of Electrochemical Energy Conversion and Storage, 17(4), 032020. 044701.

[5] R. Ducret. Livraison de colis et logistique urbaine: quelles recompositions de la messagerie en milieu urbain? Revue française de gestion industrielle, 2012

[6] EVSpecifications. 2017 tesla model s 90d - specifications.

[7] S. Senouci N. Kroichvili C. Cappelle D. Fass F. Gechter, E. Aglzim. Transportation of goods in inner-city centers: Can autonomous vehicles in platoon be a suitable solution? In 2017 IEEE Vehicle Power and Propulsion Conference (VPPC), pages 1-5, 2017.

[8] Sandia National Lab. Data for degradation of commercial lithium-ion cells as a function of chemistry and cycling conditions.

[9] M. Polycarpou M. Mavrovouniotis, G. Ellinas. Ant colony optimization for the electric vehicle routing problem. IEEE Symposium Series on Computational Intelligence SSCI, 2018.

[10] El.Aglzim O.Grunder S.Senouci P.Romet, F.Gechter. Towards an environment approach to determine the ant colony termination criterion. IWIS2020, 2020.

[11] P. Reme-Harnay. L'emprise des sous-traitants de la messagerie vis à vis de leurs donneurs d'ordres : entre dépendance économique et reconnaissance professionnelle. Colloque Les formes contemporaines de l'apos, 2019.

[12] T. Caric T. ErdeliT. A survey on the electric vehicle routing problem: Variants and solution approaches. Journal of Advanced Transportation, page $48,2019$.

[13] Rui Xiong, Linlin Li, and Jinpeng Tian. Towards a smarter battery management system: A critical review on battery state of health monitoring methods. Journal of Power Sources, 405:18-29, 2018. 